University of Nebraska - Lincoln

DigitalCommons@University of Nebraska - Lincoln

7-1-2007

\title{
Pilot Study on Real-Time Calculation of Arrival Type for Assessment of Arterial Performance
}

\author{
Edward J. Smaglik \\ Purdue University \\ Darcy M. Bullock \\ Purdue University, darcy@purdue.edu \\ Anuj Sharma \\ University of Nebraska - Lincoln, anujs@iastate.edu
}

Follow this and additional works at: https://digitalcommons.unl.edu/civilengfacpub

Part of the Civil Engineering Commons

Smaglik, Edward J.; Bullock, Darcy M.; and Sharma, Anuj, "Pilot Study on Real-Time Calculation of Arrival Type for Assessment of Arterial Performance" (2007). Civil Engineering Faculty Publications. 14. https://digitalcommons.unl.edu/civilengfacpub/14

This Article is brought to you for free and open access by the Civil Engineering at DigitalCommons@University of Nebraska - Lincoln. It has been accepted for inclusion in Civil Engineering Faculty Publications by an authorized administrator of DigitalCommons@University of Nebraska - Lincoln. 
Published in the Journal of Transportation Engineering (July 2007), 133(7): 415-422.

Copyright 2007, ASCE. DOI: 10.1061/(ASCE)0733-947X(2007)133:7(415).

Used by permission.

\title{
Pilot Study on Real-Time Calculation of Arrival Type for Assessment of Arterial Performance
}

\author{
Edward J. Smaglik', Ph.D.; Darcy M. Bullock ${ }^{1}$, Ph.D., P.E.; and Anuj Sharma ${ }^{2}$ \\ ${ }^{1}$ Department of Civil Engineering, Purdue University, West Lafayette, IN; corresponding author: darcy@purdue.edu \\ ${ }^{2}$ Department of Civil Engineering, University of Nebraska, Lincoln, NE; asharma3@unl.edu
}

Note: Discussion remained open until December 1, 2007. The manuscript for this paper was submitted for review November 7, 2005; approved February 22, 2007; published July 1, 2007.

Abstract: The Highway Capacity Manual uses the arrival type (AT) as a mechanism to account for the quality of traffic signal coordination in the calculation of delay at a signalized intersection. Although there is much discussion in the literature regarding the accuracy and precision of this approach, the AT parameter provides a simple mechanism for grading the performance of traffic signal coordination. This paper describes data collection limitations of current traffic signal controllers and proposes a procedure where the AT parameter can be calculated by traffic signal controllers in real time. Given that the nation received a score of 61 out of a possible 100 points for coordinated systems on the National Traffic Signal Report Card, this method is particularly timely as it provides an easily obtainable quantitative measure of traffic signal coordination. Data from a coordinated system in Noblesville, Ind., is analyzed and presented in a format that can be used to assess arterial performance. Results from the test site show that the quality of progression of the northbound approach was "favorable" to "highly favorable" during the p.m. coordinated period (peak direction) and "random" to "favorable" during the a.m. coordinated period (off-peak direction). As expected, the quality of progression for the northbound approach during noncoordinated periods and the southbound approach (which is approximately $1.6 \mathrm{~km}$ from the nearest upstream signal) during all periods was generally found to be "random."

CE Database subject headings: Traffic management; Traffic signals; Traffic flow; Traffic engineering; Transportation engineering; Computation.

\section{Introduction}

The arrival type (AT) in the Highway Capacity Manual (HCM) (Transportation Research Board 2000) is a measure of effectiveness used to describe the quality of progression from one signalized intersection to the next along a coordinated corridor. The AT parameter is based upon the percentage of vehicles arriving during the green indication, when they arrive during the green interval, and the density of the arriving platoon. The AT parameter can be calculated using the platoon ratio $\left(R_{p}\right)$, shown in Equation (1), and Table 1, Exhibit 15-4 in the HCM. Exhibit 10-18 in the HCM provides a qualitative definition of the different ATs; however, this research focuses on determining the AT quantitatively, and as such will focus on Table 1

$$
R_{p}=P\left(\frac{C}{g}\right)
$$

The AT parameter is important to signal operators for two reasons. First, it provides a method for accounting for delay experienced along a coordinated arterial being analyzed using the HCM delay equations. Second, it provides a measurement that can be used to assess the performance of an arterial signal system's progression quality. However, it has been shown that collecting accurate data on quality of progression using the method- ology set forth in Chapter 15 of the HCM is difficult and extremely labor-intensive, as it requires the evaluation of the performance of multiple approaches over several time periods (Eidson and Bullock 2001; Washburn and Nguyen 2003; Arasan and Kashani 2003).

Using $R_{p}$ to classify AT inherently requires cycle by cycle data measurement, a feature that currently no commercial traffic controllers provide. This cycle by cycle type of tabulation has been shown to be an effective method of categorizing data for adaptive control, offset tuning, and other signal timing measures (Abbas et al. 2001a,b; Luyanda et al. 2004; Smaglik 2005). With the use of setback detectors to record vehicle arrivals, cycle by cycle tabulation of arrivals, and collection of green indication and cycle lengths, the quality of progression can be quantified on a real-time basis. This can provide traffic engineers with the ability to easily assess signal system performance. Data from this assessment can then be used to assess traffic signal system performance, providing necessary data to address the poor grade received on the National Traffic Signal Report Card (National Transportation Operations Coalition 2005). This paper documents the methodology, data collection procedure, and results of such an analysis using detector and phase information from an instrumented intersection. 
Table 1. Relationship between Arrival Type and Platoon Ratio $\left(R_{p}\right)$ (Transportation Research Board 2000)

\begin{tabular}{llll}
\hline $\begin{array}{c}\text { Arrival } \\
\text { type }\end{array}$ & $\begin{array}{c}\text { Range of platoon } \\
\text { ratio }\left(R_{p}\right)\end{array}$ & $\begin{array}{c}\text { Default } \\
\text { value }\left(R_{p}\right)\end{array}$ & $\begin{array}{c}\text { Progression } \\
\text { quality }\end{array}$ \\
\hline 1 & $\leq 0.50$ & 0.333 & Very poor \\
2 & $>0.50-0.85$ & 0.667 & Unfavorable \\
3 & $>0.85-1.15$ & 1.000 & Random arrivals \\
4 & $>1.15-1.50$ & 1.222 & Favorable \\
5 & $>1.50-2.00$ & 1.667 & Highly favorable \\
6 & $>2.00$ & 2.000 & Exceptional \\
\hline
\end{tabular}

Methodology

Using setback detectors, vehicle arrivals are collected and tabulated into cycle by cycle bins. Equation (2) is used to calculate the proportion of vehicles arriving on green. The number of vehicles arriving on green and during the preceding red interval is used for this calculation. Figure 1 illustrates the cycle by cycle tabulation boundaries. Vehicles passing over the setback detectors during yellow are counted as red arrivals

$$
P=\left(\frac{N_{g}}{N_{r}+N_{g}}\right)
$$

In Figure 1(a), variables $N_{r}, N_{g^{\prime}} g$ and $C$ from Equation (2) are shown graphically, with a total of four vehicles arriving on red and five vehicles arriving on green. Figure 1(b) illustrates the cycle by cycle binning across three separate cycles. With cycle by cycle binning, the precision of each cycle's data is not lost, as it would be if 5 or 10 minute bins were used. For example, if $C 1, C 2$, and $C 3$ were placed into one large bin, the percent arriving on green would be $53 \%$, and the individual values of 20,60 , and $80 \%$ would be overlooked. More importantly, controllers currently have no provision to separately tabulate arrival counts during the green and red times of a cycle. Using the proportion of vehicles arriving on green along with their corresponding green interval and cycle lengths, $R_{p}$ can be calculated, and the AT classified using Table 1 .

Table 1 defines discrete bins, but it is more useful to have a continuous variable for characterizing the AT. For this study, a piecewise continuous relationship between the platoon ratio and AT was defined. For example, a platoon ratio of 0.5 is the threshold between AT 1 and AT 2 , and a platoon ratio of 0.85 is the threshold between

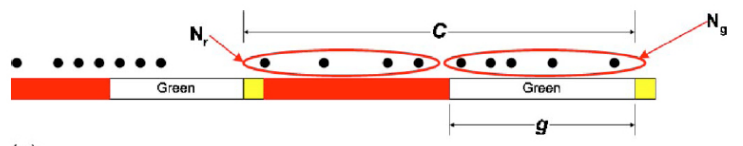

(a)

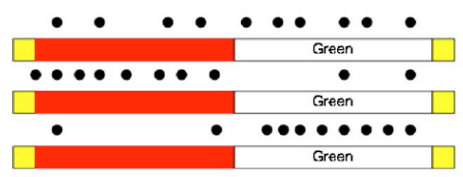

Percent Arrival on Green

$60 \%$

$20 \%$

$80 \%$

(b)

Figure 1. Data bin for calculation of proportion of vehicles arriving on green $(\mathrm{P})$ : (a) binning of vehicle arrivals during different indications; (b) cycle by cycle binning.

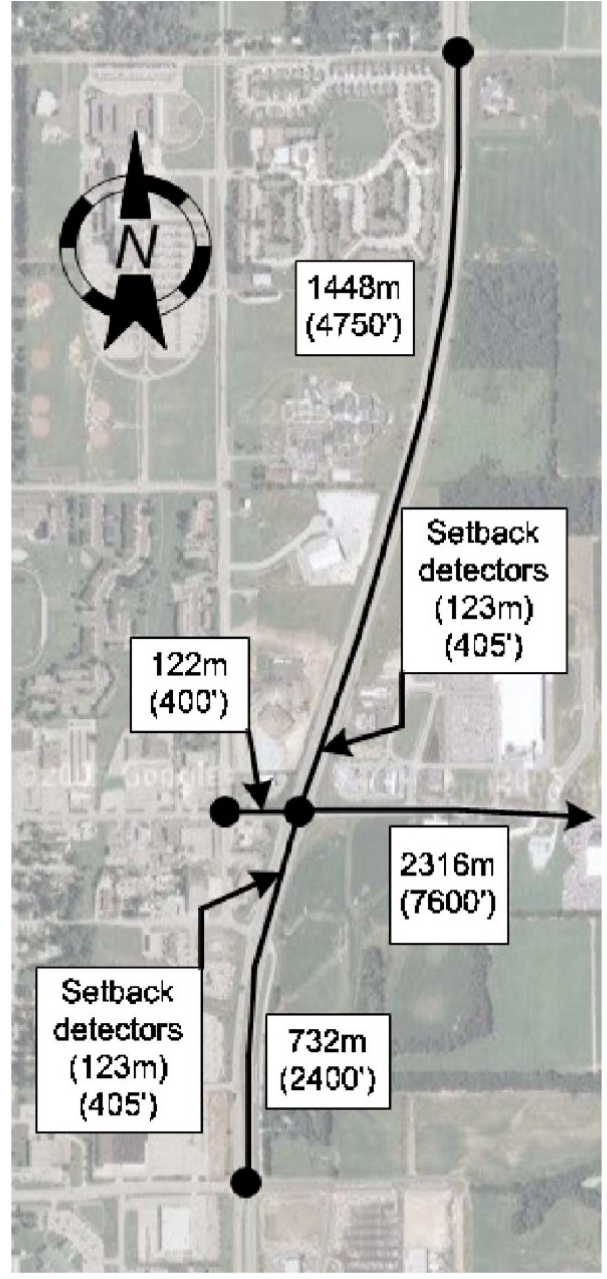

Fig. 2. Adjacent intersections

AT 2 and AT 3. Linear interpolation is used between these thresholds to provide a continuous estimate of AT based upon the platoon ratio.

\section{Data Collection Site and Existing Conditions}

Data were collected at the Indiana Department of Transportation's (INDOT) intersection testbed in Noblesville, Ind. This site is instrumented with 12 Autoscope Solopro detection units for data collection purposes. While these data collection units are typically used for video detection, they have the capability of receiving eight inputs, such as phase indication and detector status. The status of these inputs can then be overlaid on recorded video as well as logged to a time-stamped event data file. The field conditions can then be observed later, and verified with the recorded video. For future data collection, the writers of this paper are working closely with a controller manufacturer to provide time-stamped contact closures for phase indications as well as vehicle detectors as a standard controller feature.

Figure 2 is an aerial view of the testbed intersection along with the adjacent area. Distance to the nearest intersection in each direction is shown, as well as the location of the setback detectors on both the northbound and 
southbound approaches. Data used for this study were collected on these approaches, with the section of roadway immediately north of the intersection experiencing an average annual daily traffic (AADT) of 24,080. The intersection is controlled by an actuated controller, and operates a typical eight-phase dual-ring structure, with coordination in the northbound/southbound directions during the a.m. peak and p.m. peak timing periods, and in the eastbound/westbound directions during the midday and off-peak timing periods. The northbound and southbound approaches are high speed approaches $(88$ $\mathrm{km} / \mathrm{kph}, 55$ miles/hour) with setback detectors located 123 meters (405 feet) back from the stopbar. With each lane wired into the data collection unit on a separate channel, vehicle arrivals over the setback detectors in both through lanes (Lanes A and B) as well as the right turn lane (Lane $\mathrm{C}$ ) on each respective approach were collected separately over a 24 -hour period, placed into cycle by cycle bins, and then combined to provide progression data on an approach basis. While the Highway Capacity Manual states that " $P$ should be determined as the proportion of vehicles in the cycle that arrive at the stop line or join the queue (stationary or moving) while the green is displayed," this research used a static collection location, as it is not feasible to collect vehicle arrivals at a point which will constantly move (back of queue), unless the collection is manually done.

\section{Data Collection and Analysis}

Data were collected in 24-hour intervals. Figure 3 shows the percent of vehicles arriving on green for both the northbound and southbound approaches. For smoothing purposes, a 20-cycle moving average was used. This value was chosen because it removed enough noise to allow for easier examination of the data without removing relevant fluctuations. Also shown on these figures are trace lines which are $1 \mathrm{SD}$ above and below the 20-cycle moving average. These trace lines provide insight into the variability of the arrivals on green. Finally, plotted on these graphs are instances when a detector in an individual lane remained occupied for greater than $10 \mathrm{sec}-$ onds. This highlights instances where the queue backed up over the setback detection area, and as such, vehicle arrivals on red may be understated. Occurrences are plotted separately for each lane (Queue Lane A, Queue Lane B, and Queue Lane C). Time of day (TOD) pattern changes are implemented through the coordinated system, and are shown by the vertical lines in Figure 3.

In Figure 3(a), the percent of vehicles arriving on green in the northbound direction, the moving average hovers around $50 \%$ for most of the day (with the exception of free periods), with improvement during the p.m. peak period. Coordination during the p.m. period is provided between the study intersection and the closest upstream intersection [732 meters (2,400 feet) to the south], as shown in Figure 2. At this location, volume on the northbound movement peaks during the p.m. period, and the impact of the pattern change can be seen as the percent of arrivals on green increases to around $60 \%$ at the onset of this period, then drops off sharply as the pattern changes at the end of the p.m. period. Regarding the standard deviation trace lines, there is much more variability during the free periods than during the coordinated times of the day. This is expected, as there is no metering of arrivals during free operation. Finally, traffic in Lane A queues over the detector during this period, as would be expected during the busiest time of the day, however there was no queuing in Lane B or Lane $C$. The queuing in Lane A was logged by the detector and shown as a triangular entry on the upper portion of the graph. Queuing over the back detectors will understate the arrivals on red to some degree, but the impact of this was not quantified in this pilot study.

Figure 3(b) shows the percent arrivals on green for the southbound approach, whose volume peaks during the a.m. period. Although there is a signal 1,448 meters $(4,750$ feet) upstream, as shown in Figure 2, random arrivals result in essentially a uniform distribution, because this upstream signal is not in the coordinated system.

Consequently, there is no pronounced change in percent arrivals on green when the a.m. plan takes or leaves effect. Regarding the standard deviation trace lines, the change in variability of the arrivals on green throughout the day is similar to that seen on the northbound approach, with less variability during coordinated operation. Finally, only traffic in Lanes A and B queued over the detector during the a.m. period, as would be expected since this is the primary travel direction in the morning.

Data collected during this evaluation were collected on a lane by lane basis, with each setback detector on its own channel (Smaglik et al. 2005). Traditionally, all setback detectors on an approach are wired together in series and share a channel. Setback detectors operating in series and on a lane by lane basis on both the northbound and southbound approaches were compared to determine if the manner in which the detectors are wired together has an impact on the clarity of the data.

Over a 24 hour period, it was determined that the manner in which the detectors are wired (shared or lane by lane) has little impact on the reported percent of vehicles arriving on green. During time periods where a setback detector remains occupied for a period of time due to queued traffic, such as between 6:30 a.m. and 8:00 a.m. in Figure $3(b)$, some precision is lost when the setback detectors share a channel; however this has a relatively minor impact on the reported percents of arrivals on green.

\section{Relationship between Flow Profile and Computed Ar- rival Type}

Figures 4 and 5 are included to provide additional insight into the arrival type plots shown in Figure 3. These figures illustrate the relationship between arriving vehicle platoons and the corresponding phase green indication for the northbound and southbound approaches during 

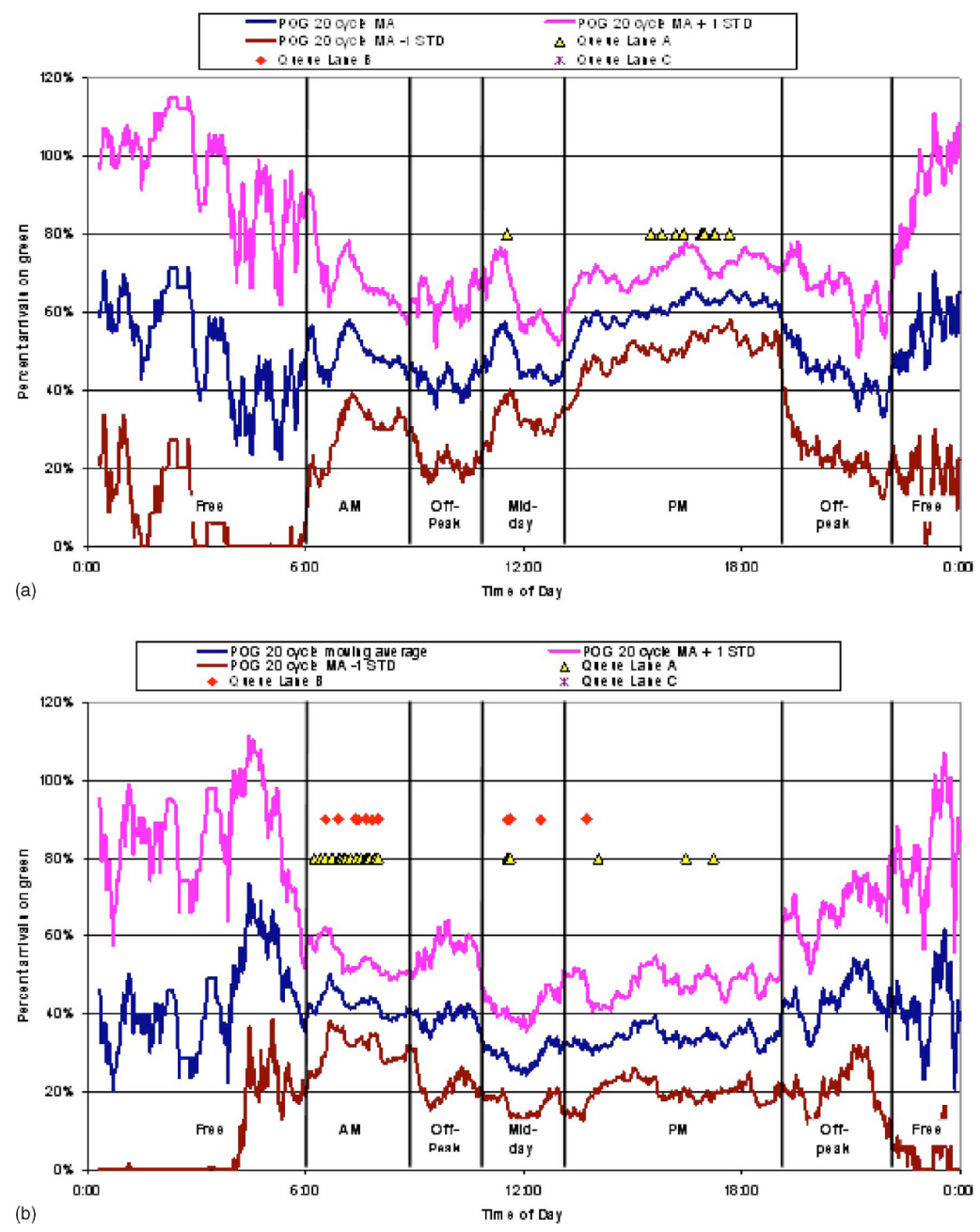

Fig. 3. Percent arrival on green (POG), August 9, 2005: (a) northbound approach, POG; (b) southbound approach, POG

a weekday p.m. period.

Figure $4(\mathrm{a})$ is a cumulative distribution that shows at what point in each cycle the northbound indication changed to green during the p.m. period. During approximately $80 \%$ of the cycles, the through movement indication turned green about 70-80 seconds into the cycle. Figure 4(b) documents the cycle-based flow profile (platoons) on the northbound approach during the same time period. The majority of vehicles arrived during the portion of the cycle which was green, which is consistent with $60 \%$ of vehicles arriving on green shown in Figure 3 . Figure 5(b) shows the cumulative onset of green distribution for the southbound approach. The indication turned green about 80-90 seconds into the cycle during most cycles, slightly later than the northbound indication. However, in contrast to Figure 4(b), the cycle-based flow profile shown in Figure 5(b) for the southbound movement shows essentially uniform arrivals throughout the cycle, consistent with that shown in Figure 3.

\section{Analysis of Arrival Type Data}

Figure 6 shows the AT for the data previously shown in Figure 3(a). To produce the ATs shown in Figure 6, the proportion of vehicles arriving on green along with the length of green indication and cycle length were input into Equation (1) to calculate the platoon ratio. The platoon ratio was then classified with Table 1 to produce the arrival type, or applied to the interpolation described earlier to generate the estimated continuous arrival type. The trace line shown in Figure 6 is a 20-cycle moving average of the actual points. The analysis of arrival type data will focus on coordinated operation. Arrival types during free operation may not be very representative of actual vehicle arrivals, as excessively long or short cycle lengths and green intervals provide a very large impact on the platoon ratio (Equation (1)), overshadowing the percent of vehicle arrivals on green. Regarding coordinated operation, in Figure 6, the AT during the p.m. peak period is either 4 or 5 , defined by the HCM as favorable or highly favorable, respectively. ATs during other time periods of the day were not as good. For example, the AT drops quickly from AT 5 to AT 3, and eventually down to AT 2 after the p.m. period transitions to the off-peak period. While Figure 6 does not encompass the complete picture, as the intersection provides coordination in a different direction during the midday and off-peak periods, investigation into the poor arrival types on this approach during these time periods would be warranted. 

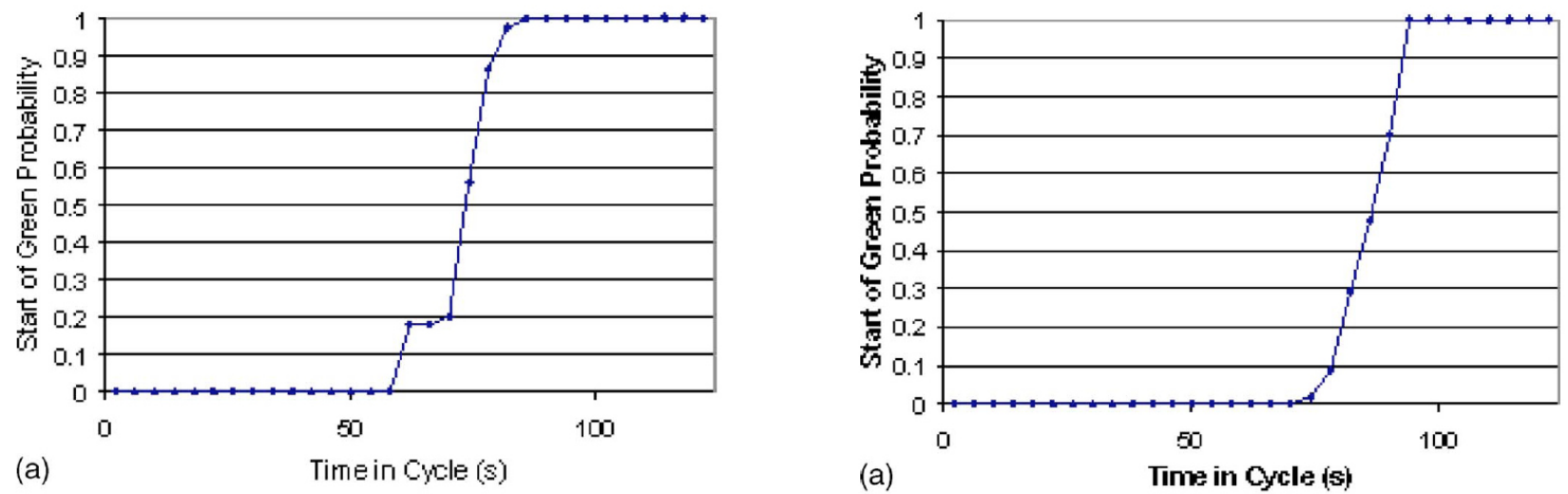

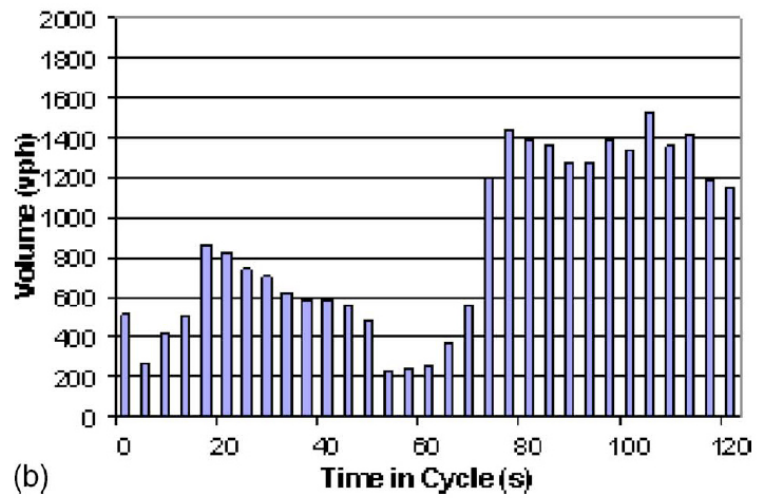

Fig. 4. Northbound p.m. peak: (a) start of green time cumulative distribution; (b) cycle-based flow profile

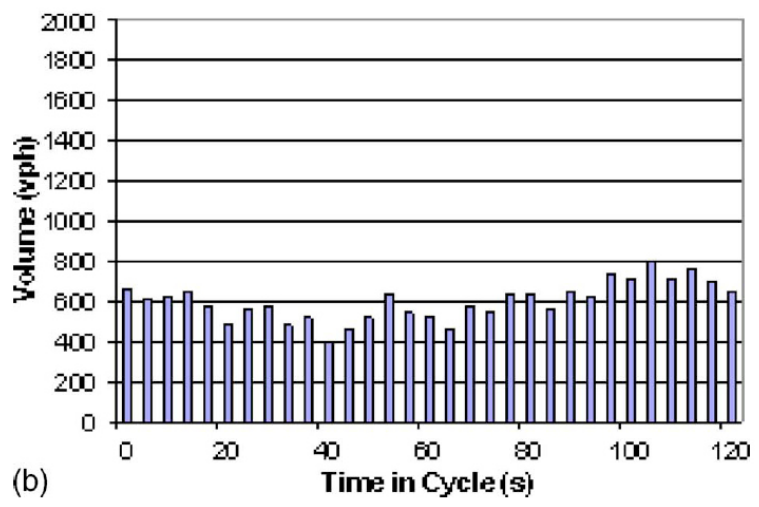

Fig. 5. Southbound p.m. peak: (a) start of green time cumulative distribution; (b) cycle-based flow profile

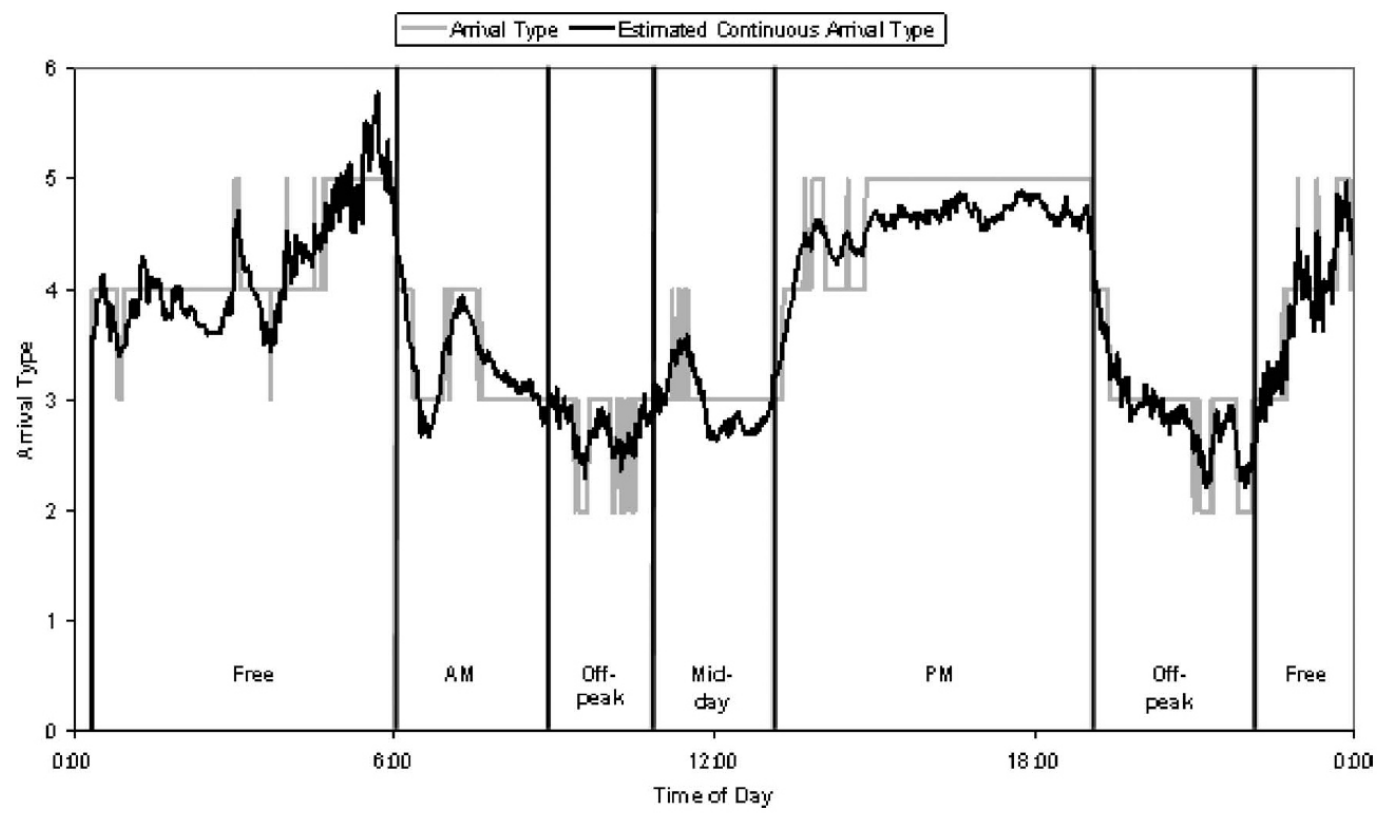

Fig. 6. Northbound approach arrival type, August 9, 2005 
Arrival Type and Percent Arrival on Green (all 20 cycle moving average), Northbound Approach Phase 2, Noblesville, 08109105

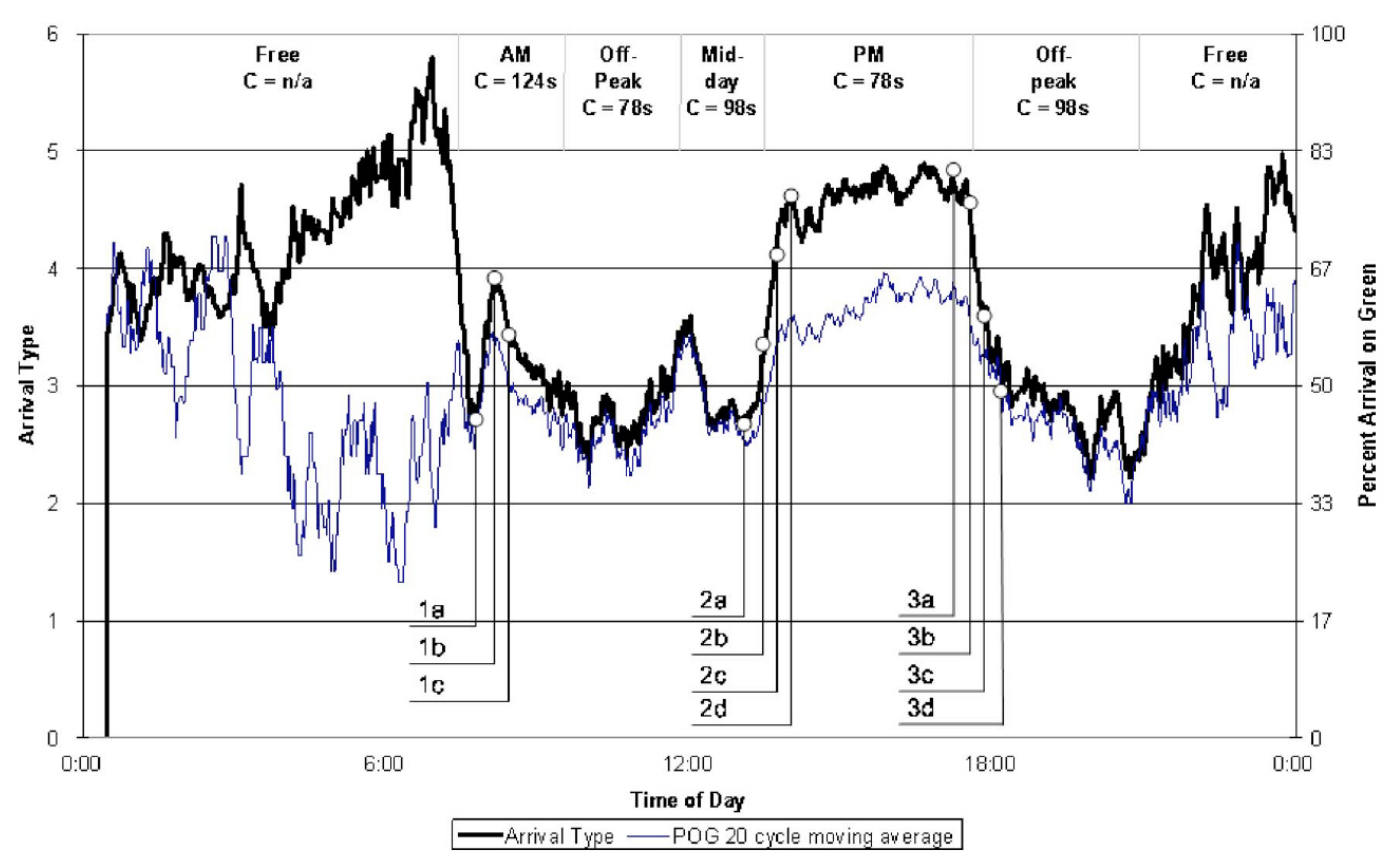

Fig. 7. Arrival type data

Figure 7 shows the percent of vehicles arriving on green and the corresponding arrival type for the northbound approach. Eleven points are called out in Figure 7. Table 2 details the data that were used to calculate these points (cycle length, green interval length, and percent arrival on green) as well as other pertinent information, such as served volume and $v / c$ ratio.

Points 1a, 1b, and 1c in Figure 7 illustrate how the AT changes quite rapidly when a new timing plan is initiated and morning volumes begin to increase around 6:00 a.m. The estimated continuous AT changes from 2.73 to 3.90 to 3.44 across the three points, respectively. This variation is attributed to the difference in the percent of vehicles arriving on green. For Point $1 \mathrm{a}, 42.6 \%$ of vehicles arrived on green. At Point $1 b$, this had increased to $56.6 \%$, while the corresponding estimated continu- ous AT increased from 2.73 to 3.90. As the percent of vehicles arriving on green dropped to $50.4 \%$ at Point 1c, the AT dropped to 3.44. As these points were all within the same plan, the cycle time did not change. Green time was at its highest at Point $1 \mathrm{~b}$, along with served volume and $v / c$ ratio, but these are not grossly larger than the other points. This variation was caused by changes in the percent of vehicles arriving on green, most likely due to flow changes at upstream intersections.

Points 2a, 2b, 2c, and 2d in Figure 7 illustrate the change in AT during another plan transition. At this point in the day, the test site transitions from the midday plan to the p.m. plan. Across these points, the AT increases from 2.71 to 4.61. Cycle time increases from 98 to 124 seconds from Point $2 \mathrm{a}$ to Point $2 \mathrm{~b}$, but remains static at 124 seconds for Points $2 \mathrm{c}$ and $2 \mathrm{~d}$. While an increase in cycle

Table 2. Values for Points Identified in Fig. 7

\begin{tabular}{|c|c|c|c|c|c|c|c|c|}
\hline Point & $\begin{array}{l}\text { Time of day } \\
\text { (h) }\end{array}$ & $C$ & $g$ & $v$ & $v / c$ & $\begin{array}{l}\text { POG } \\
(\%)\end{array}$ & $R_{p}$ & Arrival type \\
\hline 1a & 0637 & 124 & 47.8 & 17 & 0.22 & 42.6 & 1.20 & 2.73 \\
\hline $1 b$ & 0718 & 124 & 54.4 & 29 & 0.34 & 56.6 & 1.30 & 3.90 \\
\hline $1 \mathrm{c}$ & 0745 & 124 & 48.8 & 17 & 0.22 & 50.4 & 1.15 & 3.44 \\
\hline $2 \mathrm{a}$ & 1241 & 98 & 44.2 & 19 & 0.27 & 42.2 & 0.90 & 2.71 \\
\hline $2 b$ & 1315 & 124 & 41.5 & 25 & 0.38 & 48.3 & 1.10 & 3.30 \\
\hline $2 \mathrm{c}$ & 1330 & 124 & 48.4 & 40 & 0.52 & 54.3 & 1.35 & 4.10 \\
\hline $2 \mathrm{~d}$ & 1358 & 124 & 46.7 & 45 & 0.61 & 60.4 & 1.54 & 4.61 \\
\hline $3 \mathrm{a}$ & 1835 & 124 & 63.3 & 40 & 0.40 & 64.8 & 1.61 & 4.84 \\
\hline $3 b$ & 1900 & 124 & 63.3 & 27 & 0.27 & 62.1 & 1.56 & 4.67 \\
\hline $3 \mathrm{c}$ & 1920 & 98 & 29.5 & 21 & 0.45 & 54.0 & 1.20 & 3.59 \\
\hline $3 d$ & 1942 & 98 & 36.8 & 21 & 0.36 & 47.7 & 1.02 & 3.05 \\
\hline
\end{tabular}




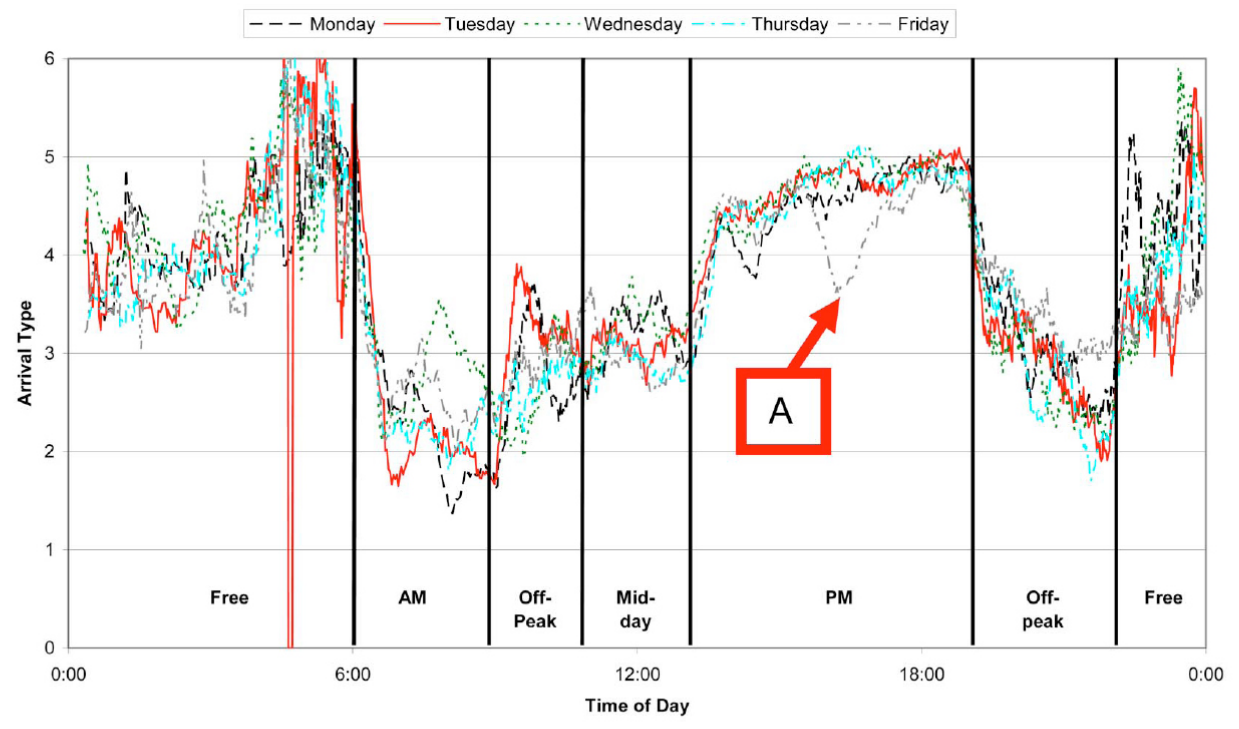

(a)

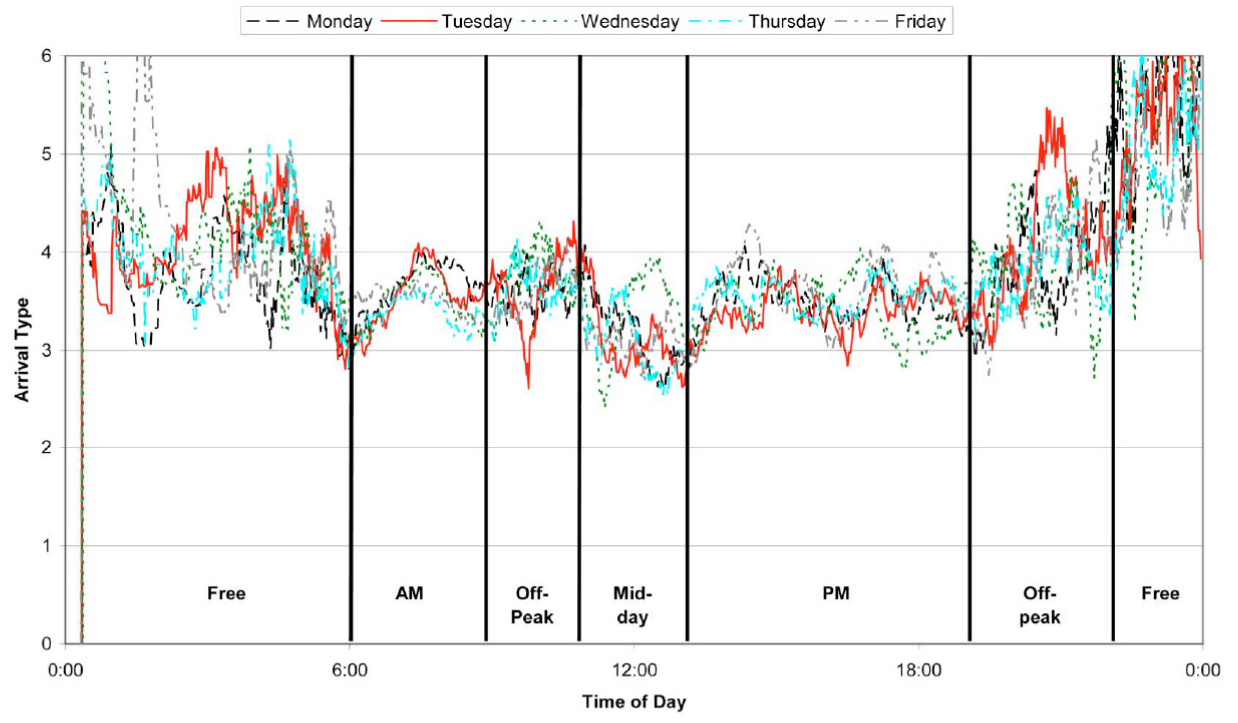

(b)

Fig. 8. Approach arrival type September 26-30, 2005: (a) northbound approach; (b) southbound approach

time will increase the platoon ratio, and thereby the AT, based upon Equation (1), the increase in percent arriving on green (from $42.2 \%$ at Point $2 \mathrm{a}$ to $60.4 \%$ at Point $2 \mathrm{~d}$. causes the improvement in AT. Most likely, the increase in percent arriving on green is due to an offset change, as green time is relatively static while volume increases across the points. The increase in $v / c$ ratio from 0.27 at Point $2 \mathrm{a}$ to 0.60 at Point $2 \mathrm{~d}$ reflects this. This type of data implies that switching to the p.m. plan earlier may improve operations on this approach.

Points 3a, 3b, 3c, and 3d illustrate the change in AT during the plan transition from p.m. to off peak. Cycle length drops from 124 to 98 seconds, and green time drops quite a bit as well, from 63.3 seconds for Points $3 a$ and $3 b$ to 29.5 and 36.8 seconds for Points $3 c$ and $3 d$.

While both of these values dropped, the ratio of cycle to green time increased. Volume dropped, but the decrease in green time caused the $v / c$ ratio to remain relatively stable. The decrease in percent arrivals on green (64.8\% at Point 3 a to $47.7 \%$ at Point $3 \mathrm{~d}$ ) was large enough to overshadow the $\mathrm{C} / \mathrm{g}$ ratio increase, causing the AT to drop from 4.84 to 3.05. During this transition period, the drop in AT was likely caused by an offset change as well as a split change. These data imply that extending the p.m. plan may improve operations on this approach.

Figure 8 shows the AT on both the northbound and 
southbound approaches for a full week. Across the entire week, the ATs are fairly consistent on both approaches, except perhaps the northbound approach on Friday.

In Figure 8(a), Point A highlights an inconsistency on the northbound approach during the p.m. peak period. At this time during the p.m. period, the AT is very close to 5 during all but one day of the week; however Point A shows that the estimated continuous AT dipped to about 3.5 during one afternoon. Investigation of the corresponding video confirmed the validity of the data. The actual cause of this drop in AT is unknown, as it fell outside of the view of the data collection unit, however it was likely due to an upstream disturbance such as maintenance work on the roadway or signal.

In Figure 8(b), the AT for the southbound direction oscillates between AT 3 and AT 4, random and favorable, respectively, as defined by the HCM. Given the lack of coordination from the upstream intersection on this movement, this is as expected, considering the typical split provided to this movement is in the area of $30-40 \%$.

\section{Conclusions}

To provide engineers with a method to easily assess a signal system's performance, an online quantitative progression quality assessment tool is needed. While there are several issues to be addressed through future research, such as the understatement of vehicle arrivals on red as the queue covers the setback detectors and the most effective moving average for data smoothing purposes, this research has provided a method to easily assess the performance of a coordinated arterial on a signal by signal basis through minimal data collection requirements. By collecting phase status and time-stamped vehicle arrivals, arrival types can be generated in real time. Unfortunately, all traffic signal controllers currently bin data into arbitrary bin sizes of 5 or 10 minute intervals without regard to signal indication color or correlation with the cycle time. While this does present a short-term implementation issue, the example results presented in this paper may provide the motivation for agencies to update controller specifications to provide the required data necessary for generating these results in real time. The NTCIP 1202 (National Transportation Communications for ITS Protocol 2005) specification is quite likely the most appropriate standard for specifying such a capability.

\section{Acknowledgments}

This work was supported the Joint Transportation Research Program administered by the Indiana Department of Transportation and Purdue University. The contents of this paper reflect the views of the writers, who are responsible for the facts and the accuracy of the data presented herein, and do not necessarily reflect the official views or policies of the Indiana Department of Transportation. These contents do not constitute a standard, specification, or regulation.

\section{Notation}

The following symbols are used in this paper:

$C=$ cycle length (s);

$g=$ length of green interval;

$N_{g}=$ number of vehicles arriving on green;

$N_{r}^{g}=$ number of vehicles arriving on red;

$P=$ proportion of all vehicles arriving during green;

$R_{p}=$ platoon ratio;

$v=$ served volume (vehicle); and

$v / c=$ volume to capacity ratio.

\section{References}

Abbas, M., Bullock, D. M., and Head, L. (2001a). “A real-time offset transitioning algorithm for coordinating traffic signals." Transportation Research Record. 1748, Transportation Research Board, Washington, D.C., 26-39.

Abbas, M., Bullock, D. M., and Rhodes, A. (2001b). "Comparative study of theoretical, simulation, and field platoon data." Traffic Eng. Control, 42 (7), 232-236.

Arasan, V. T., and Kashani, S. H. (2003). "Modeling platoon dispersal pattern of heterogeneous road traffic." Transportation Research Record. 1852, Transportation Research Board, Washington, D.C., 175-182.

Eidson, W. C., and Bullock, D. M. (2001). “Analysis of arrival type estimation procedures." Transportation Research Record. 1776, Transportation Research Board, Washington, D.C., 123-127.

Luyanda, F., Gettman, D., Shelby, S., Head, L., Bullock, D. M., and Mirchandani, P. (2004). "ACS-lite algorithmic architecture: Applying adaptive control system technology to closed-loop traffic signal control systems." Transportation Research Record. 1856, Transportation Research Board, Washington, D.C., 175-184.

National Transportation Communications for ITS Protocol. (2005). Object definitions for actuated signal controller (ASC) units, v1.07d, AASHTO, NEMA, and ITE.

National Transportation Operations Coalition. (2005). National Traffic Signal Report Card. (http:/ / www.ite.org/reportcard/ TSNRC-NTOC.ppt) (October 17, 2005).

Smaglik, E. J. (2005). “Enhanced Tactical and Strategic Control Methods for Traffic Signal Operation." Doctoral dissertation, Purdue University, West Lafayette, Indiana.

Smaglik, E. J., Bullock, D. M., and Urbanik, T., (2005). “An evaluation of lane by lane vehicle detection for actuated controllers serving multi-lane approaches." Transportation Research Record. 1925, Transportation Research Board, Washington, D.C., $123-133$.

Transportation Research Board. (2000). Highway Capacity Manual. National Research Council, Washington, D.C.

Washburn, S. S., Courage, K. G., and Nguyen, T. (2003). “Integrated simulation-based method for estimating arrival type for signalized arterial planning applications." Transportation Research Record. 1852, Transportation Research Boand, Washington, D.C., 69-76. 